\title{
A Clinical Approach to Intrahepatic Cholestasis of Pregnancy
}

\author{
Zaid Diken, MD ${ }^{1}$ Ihab M. Usta, MD ${ }^{1}$ Anwar H. Nassar, MD ${ }^{1}$ \\ ${ }^{1}$ Department of Obstetrics and Gynecology, American University of \\ Address for correspondence Anwar H. Nassar, MD, Department of \\ Beirut Medical Center, Beirut, Lebanon \\ Obstetrics and Gynecology, American University of Beirut Medical \\ Center, Beirut, Lebanon (e-mail: an21@aub.edu.lb).
} Am J Perinatol 2014;31:1-8.

\begin{abstract}
Keywords

- intrahepatic cholestasis of pregnancy

- epidemiology

- etiology

- diagnosis

- management

Intrahepatic cholestasis of pregnancy (ICP) has a varying prevalence worldwide. The etiology behind this disease remains not fully understood with multiple factors influencing its development including genetic variations, dietary factors, hormonal changes, and environmental influences. Presenting mainly during the third trimester with generalized itching and resolving spontaneously postpartum, this condition is still associated with fetal morbidity and mortality. The diagnosis is based on clinical presentation in association with biochemical abnormalities. Elevation in total bile acid levels is the most frequent laboratory abnormality and seems to be the most important for gauging further management of the disease. The most appropriate gestational age for the delivery of women with ICP is yet to be determined. In this review we discuss the epidemiology, clinical features, diagnosis, etiology, and management of ICP, trying to shed light on some controversial aspects of the disease.
\end{abstract}

Historically, intrahepatic cholestasis of pregnancy (ICP) has also been referred to as obstetric cholestasis, jaundice in pregnancy, idiopathic jaundice of pregnancy, hepatosis gestationalis, or obstetric hepatosis. ${ }^{1}$ Originally described by Ahlfeld in 1883 , ICP is a liver disease unique to pregnancy. ${ }^{1}$ Its prevalence varies widely with geographic location and ethnic origin. $^{1-3}$ It ranges from 0.5 to $1.5 \%$ in Europe to 0.3 to $5.6 \%$ in the United States, according to ethnicity. ${ }^{1,3,4}$ The highest frequencies are reported in Chile, Bolivia, and Scandinavia, a finding that was attributed to dietary factors. ${ }^{5}$ However, the prevalence has recently dropped from 11.8 to $27.7 \%$ to 1.4 to $4.0 \%$ in Chile. ${ }^{6,7}$ During the same period, the prevalence in Scandinavia decreased from $2.0 \%$ to 0.1 to $1.5 \%{ }^{8}$ There is no clear explanation for this drop but it has been attributed to changes in environmental factors, like seasonal variation, selenium deficiency, and hepatitis $C$ infection. ${ }^{1}$ Equally unclear are the mechanisms by which the fetal complications occur. This article reviews the epidemiology, clinical features, diagnosis, etiology, and management of ICP, trying to shed light on some controversial aspects of the disease.

\section{Etiology}

Risk factors for ICP include ethnicity, twin gestation, ${ }^{9}$ assisted reproductive techniques, ${ }^{10}$ hepatitis $\mathrm{C},{ }^{11}$ advanced maternal age, family history of biliary disease, preeclampsia, ${ }^{12}$ and ICP in previous pregnancy. ${ }^{13}$ In addition, women with ICP seem to have higher incidence of gallstones and drug sensitivities and more severe and prolonged emesis. ${ }^{14,15}$

The etiology of ICP is heterogeneous and not fully understood, likely resulting from the cholestatic effects of pregnancy hormones and their metabolites in genetically predisposed women. Multiple factors have been implicated in the pathogenesis of ICP including environmental influences, nutritional deficiencies, hormonal changes, and genetic variations. ${ }^{16} \mathrm{~A}$ seasonal variation in the frequency of ICP has been observed with a higher prevalence noted in winter. ${ }^{17}$ Deficiency in selenium, a cofactor for several oxidative hepatic enzymes, has been investigated as a contributing factor. Its deficiency is thought to lead to defective bile formation or secretion. ${ }^{18,19}$ Serum selenium levels were found to be lower in Chilean women with ICP particularly in winter due to seasonal received

October 18, 2012

accepted after revision

November 28, 2012

published online

January 28, 2013
Copyright (c) 2014 by Thieme Medical Publishers, Inc., 333 Seventh Avenue, New York, NY 10001, USA. Tel: +1(212) 584-4662.
DOI http://dx.doi.org/ 10.1055/s-0033-1333673. ISSN 0735-1631. 
variations in consumption of vegetables containing this trace mineral. ${ }^{18,19}$ It was also proposed that a total increase in plasma selenium levels was associated with the drop in ICP prevalence in Chile in the last 10 years. ${ }^{18}$ Vegetables containing selenium include garlic, onions, sunflower seeds, and mushrooms. The activity of the selenoenzyme glutathione peroxidase that positively correlates with selenium levels was also found to be lower in women with ICP. ${ }^{19}$

Evidence supports the role of steroid hormone levels as a trigger of the disorder. Symptoms typically occur in the latter part of pregnancy, when the levels of estrogen and progesterone are at their highest. ${ }^{16,20}$ In addition, symptoms resolve postpartum after hormone levels have normalized. ${ }^{21} \mathrm{Re}-$ sponse to hormones can explain the higher prevalence noted in twin gestations and recurrence of cholestasis in women with history of ICP when using combination oral contraceptive pills. ${ }^{16}$ Furthermore, Meng et al suggested an alteration in the reductive metabolism of progesterone in ICP, resulting in increased formation of metabolites and saturation of hepatic enzymes normally used for biliary secretion. ${ }^{22}$

The interaction between steroid levels, selenium, and selenoenzyme glutathione peroxidase at the molecular level of the hepatocyte is complex. As estrogen levels increase during pregnancy, the oxidative stress on the liver also increases. In patients with low levels of selenium and glutathione peroxidase, the oxidative damage of estrogens cannot be properly counterbalanced. This leads to damage of the hepatocytes and decreases their ability to excrete bile. ${ }^{19}$

Recent studies have focused on the potential role of certain genetic aberrations in the etiology of ICP. This could explain the familial and ethnic clustering of this disorder, the high recurrence rate of $\mathrm{ICP}^{23}$ and the presence of a 12 -fold increased risk of developing ICP in sisters of affected patients. ${ }^{24}$ The candidate genes causing ICP were suggested after identification of mutated genes in inherited cholestasis disorders, particularly progressive familial intrahepatic cholestasis types 1 to 3 (PFIC1-3) and benign recurrent intrahepatic cholestasis (BRIC).

Jacquemin et al were the first to provide evidence for a genetic basis of ICP. They described heterozygous gene defect in multidrug resistant protein 3 (MDR3) P glycoprotein, a canalicular phospholipid translocator involved in the biliary secretion of phospholipids. ${ }^{25,26}$ Such mutations can lead to altered bile acid trafficking, which in turn leads to elevation in bile acids. ${ }^{27}$ In fact, the most commonly studied gene is $A B C B 4$, which encodes for MDR3. A common variant of $A B C B 4$ has been linked to the development of severe forms of ICP. ${ }^{28}$

$A B C B 11$ encoding for bile salt export pump (BSEP) may also have a role in the development of ICP. A single nucleotide polymorphism in ABCB11 and lower placental levels of BSEP were found to be significantly associated with ICP. ${ }^{29,30} \mathrm{An}$ other gene that has been inconsistently linked to ICP is ATP8B1 encoding for a P-type ATPase. ${ }^{24}$ After the identification of homozygous inactivating mutations of ATP8B1 in the causality of PFIC1 and BRIC, and the clinical coincidence of both diseases with ICP in a minority of cases, Müllenbach et al were able to identify the existence of ATP8B1 mutations in ICP patients in different variations. ${ }^{24}$ Despite this, it should be stressed that genetic mutations are noted in a very small percentage of patients presenting with ICP. ${ }^{31,32}$ One study even excluded the association of all three genes with ICP. ${ }^{31}$ This adds to the heterogeneity of the disease and its multifactorial etiology.

\section{Clinical Presentation}

ICP usually manifests during the second or third trimester by pruritus and skin lesions caused by scratching. Although $80 \%$ of cases have been described after 30 weeks' gestation, ${ }^{33}$ ICP has been diagnosed as early as 8 weeks. ${ }^{34}$ The itching is classically described as total-body itching that is usually localized to the palms of the hands and the soles of the feet before it spreads to the entire body. ${ }^{35}$ It might have a nocturnal predominance and typically becomes progressively more severe with advancing gestation. ${ }^{1,35}$ Itching can be the only presenting symptom without any pronounced laboratory abnormalities or might precede any liver function abnormalities and tends to recur in 40 to $60 \%$ of subsequent pregnancies. $^{5,34,35}$ There are no associated dermatologic features apart from skin excoriations. However, pruritus is common in pregnancy and, therefore, the diagnosis of ICP has to be confirmed by laboratory tests and to rule out other etiologies like autoimmune hepatitis, hepatitis B, hepatitis C, and gallbladder disease. ${ }^{1}$ The pruritus is thought to be secondary to the accumulation of bile salts in the skin. ${ }^{16}$ Mild jaundice develops in 10 to $15 \%$ of cases, and steatorrhea is a less frequently reported symptom. ${ }^{1,36}$ Constitutional symptoms have also been reported and include anorexia, malaise, and abdominal pain. ${ }^{1}$

\section{Laboratory Abnormalities}

The most frequent laboratory abnormality noted in ICP is elevation in the serum total bile acid concentration (TBA). In one study, TBA $>11.0 \mu \mathrm{mol} / \mathrm{l}$ was shown to be the most predictive marker in the early diagnosis of ICP. ${ }^{17}$ However, there is a wide variability in what is considered abnormal TBA, values of which vary depending on the method of measurement used, fasting status, population studied, and gestational age at diagnosis. ${ }^{16,20}$ The suggested diagnostic cutoff for the diagnosis of ICP is 10 to $14 \mu \mathrm{mol} / \mathrm{L}$. The disease can be divided into mild with TBA ranging from 10 to 40 $\mu \mathrm{mol} / \mathrm{L}$ or severe with TBA levels $>40 \mu \mathrm{mol} / \mathrm{L} .{ }^{20}$ Bile acids are usually reported as cholic acid (CA), chenodeoxycholic acid (CDCA), deoxycholic acid and their summation as total bile. Bile acid ratios (CD to CDCA) differ between normal pregnancies and ICP with a mean of 1.1 in the earlier and 3.4 in the latter. However, this ratio does not seem to be of any diagnostic significance, leaving the use of TBA and hepatic transaminases sufficient for biochemical diagnosis. ${ }^{37}$ Other abnormalities include elevations in bilirubin, alanine aminotransferase, aspartate aminotransferase, alkaline phosphatase, and gamma glutamyl transferase. ${ }^{38}$ There is, however, no consensus on the cutoff level of liver enzyme elevation that is diagnostic of ICP. ${ }^{20}$ Glutathione S-transferase (GST), an indicator of hepatocellular damage, is considered by some as a 
better diagnostic marker than the traditional markers of liver function. ${ }^{38}$ There seems to be a correlation between GST and TBA; the rise of GST might precede that of the latter.

Generally, ICP disappears spontaneously after delivery, usually within 48 hours. ${ }^{1,20}$ The hepatic impairment is typically transient with liver function tests normalizing at 2 to 8 weeks postpartum. ${ }^{1}$ In some cases, persistence of biochemical abnormalities up to 34,45 , and 82 weeks postpartum has been reported. ${ }^{1,39}$

\section{Associated Obstetric Complications}

There is a clear association between ICP and adverse perinatal outcome including a higher frequency of fetal distress, preterm labor and delivery, unexplained fetal demise, and meconium staining (-Table 1). ${ }^{22,40-42,48,49}$ Earlier studies reported perinatal mortality rates as high as $11 \%$, although more recent literature estimates perinatal mortality rate at 3.5\%. ${ }^{41,42}$ However, Williamson et al reported an intrauterine mortality rate of $7 \%$ with $90 \%$ of cases occurring following 37 weeks' gestation. ${ }^{14}$ In addition, there are some reports of the coexistence of ICP with preeclampsia, ${ }^{14,43}$ acute fatty liver of pregnancy, ${ }^{33,44}$ and gestational diabetes. ${ }^{43}$ Maternal postpartum hemorrhage as a result of malabsorption of vitamin $\mathrm{K}$ has been infrequently reported in the literature. ${ }^{42}$

It is uncertain whether there is a critical bile acid threshold below which adverse pregnancy outcome can be avoided. ${ }^{16}$ Glantz et al reported an increased fetal complication rate with TBA levels $>40 \mu \mathrm{mol} / \mathrm{L}^{45} \mathrm{~A}$ more recent study even stated that the rate of complication increased only when TBA levels exceeded $100 \mu \mathrm{mol} / \mathrm{L}^{46}$

As cholestasis sets in, levels of bile start increasing in the mother, and with the ability to cross the placenta, bile starts moving from the maternal to the fetal compartment and accumulating in the cord blood serum, meconium, and amniotic fluid. ${ }^{47}$ Until now, the mechanism of adverse fetal outcome in ICP is not fully understood. Bile gets conjugated with taurine or glycine in the liver before being secreted. Studies have shown that the excessive rise of bile acid derivatives, mainly tauroconjugated bile acids, cause abnormal cardiac activity in rats mediated by their action on muscarinic M2 receptors, which could partly explain fetal cardiac abnormalities and sudden cardiac death in infants. ${ }^{48,49}$ Bile was also shown to cause vasoconstriction of placental vessels. ${ }^{50}$ Placental lobular villi vessels are of two types, one with surrounding smooth muscles and another without. One study has shown that the placentae of patients

Table 1 Incidence of obstetric complications in patients with intrahepatic cholestasis of pregnancy

\begin{tabular}{|l|l|}
\hline & Incidence \\
\hline Perinatal mortality rate & $3.5-11 \%^{48,49}$ \\
\hline Meconium staining & $27-45 \%^{48,49}$ \\
\hline Intrapartum fetal distress & $14-22 \%^{48,49}$ \\
\hline Preterm labor & $30-44 \%^{3,48}$ \\
\hline Preterm delivery & $36-38 \%^{16,49}$ \\
\hline
\end{tabular}

with ICP have a decreased vascular flow in lobular villi vessels with smooth muscles leading to a $29 \%$ reduction in total lobular villi vascular volume. ${ }^{51}$ Moreover, studies have documented the presence of bile-depleted surfactant levels in the lungs, making it a risk factor for the development of respiratory distress syndrome (RDS) even with mature lungs. The length of exposure and amount of bile were the two major factors in developing RDS. ${ }^{52,53}$ This might imply that earlier intervention and lowering TBA levels can lead to lower fetal mortality.

\section{Management}

\section{Medical Treatment}

Activated charcoal, guar gum, cholestyramine, dexamethasone, phenobarbital and S-adenosyl-L-methionine (SAMe) have all been used in the treatment of ICP. However, none of these agents proved to be superior to ursodeoxycholic acid (UDCA). Historically, the first study done on UDCA for the treatment of ICP was in 1991 when Mazzella et al treated a 30 -year-old primigravida diagnosed with cholestasis at 34 weeks' gestation with UDCA 600 mg divided into two doses for 20 days and showed marked improvement in all biochemical markers. ${ }^{54}$ Since then, several studies confirmed the efficacy of UDCA in relieving pruritus and normalization of bile acid levels in patients with ICP. ${ }^{5,55-57}$ None of the studies, however, have shown a beneficial effect of such treatment on fetal outcome. Very recently, a meta-analysis of nine randomized controlled trials suggested that the use of UDCA in ICP patients might have a beneficial effect on the fetus with a reduction in rate of preterm birth, fetal distress, RDS, and admission to intensive care unit. ${ }^{58}$

The current recommendation by the European Association for the Study of the Liver is UDCA 10 to $20 \mathrm{mg} / \mathrm{kg}$ per day, divided into two doses, as the first-line treatment for ICP. ${ }^{59}$ In most cases, improvement is evident within 1 to 2 weeks of initiation of therapy, and the medication is usually well tolerated by patients. The mechanism of action of UDCA is thought to be through three different effects: protection of cholangiocytes against cytotoxicity of hydrophobic bile acids, stimulation of hepatobiliary secretion, and protection of hepatocytes against bile acid-induced apoptosis. ${ }^{60}$ In the placenta, ICP was shown to decrease the ability of bile acid transport across the trophoblast from fetal to maternal circulation causing accumulation of bile acids in the fetal compartment. UDCA resulted in better bile acid exchange across the placenta by modulating its transporters and protecting the trophoblast from any changes in structure or function. ${ }^{61-63}$

There have been no reported cases of fetal toxicity associated with UDCA. A retrospective study analyzed a 12-year experience of the use of UDCA at a dose of $15 \mathrm{mg} / \mathrm{kg} / \mathrm{d}$ in women with ICP and found normal development at 3 months of age and no abnormalities after reexamination at 1 to 12 years. ${ }^{55}$ This could be secondary to the fact that it is given mostly during the third trimester when organogenesis is complete. Some reports showed no fetal adverse effects when given in the second trimester for other liver diseases 
with cholestasis. ${ }^{64,65}$ UDCA administration during first trimester has to be reserved for severe cases because there are no data supporting its safety or efficacy that early. Postpartum, UDCA can be safely used during lactation where only $0.01 \%$ of it is found in breast milk. ${ }^{66}$

Dexamethasone was thought to improve ICP by lowering feto-placental estrogen production and decreasing RDS. ${ }^{67}$ First used by Hirvioja et al, 10 ICP patients were treated with $12 \mathrm{mg}$ dexamethasone daily for one week; pruritus was relieved in all and a significant drop in estrogen levels was noticed. ${ }^{68}$ However, in a randomized controlled trial that included 130 patients, dexamethasone decreased pruritus and biochemical markers in the first week, but this was followed by a rise in bile acids until the end of the 3-week study period. The authors concluded that compared with UDCA, dexamethasone is not an effective treatment in improving pruritus and cannot be used to lower serum markers in ICP patients. ${ }^{69}$ That finding combined with the potential adverse effects of corticosteroids on the developing fetal brain limit the routine use of dexamethasone in clinical practice nowadays. $^{70}$

SAMe is a methyl donor occurring naturally in bile. It is involved in the synthesis of phosphatidylcholine, a compound with an influence on the fluidity of hepatic cell membranes. In rat models, SAMe showed an ability to reverse estrogeninduced cholestasis. ${ }^{71}$ In the treatment of ICP, studies have yielded conflicting results. In a randomized trial, daily intravenous SAMe for 20 days showed no effect on pruritus or on biochemical markers of ICP. ${ }^{72}$ However, another randomized trial found a decrease in serum markers that was less efficacious than UDCA. ${ }^{73}$ It is noteworthy that two studies found a synergistic effect on lowering ICP markers when UDCA and SAMe were combined compared with treatment with each one alone ${ }^{73,74}$; this can suggest a potential benefit of combining them in the severe cases of ICP, keeping in mind the unknown effect of their mixture on the fetus, which may require closer monitoring. ${ }^{74}$

ICP decreases the amount of bile found in the enterohepatic circulation, which can lead to malabsorption of fat soluble vitamins. Physiologically, vitamin K maintains hemostasis and protects against bleeding. Hence, it is used by physicians to protect against the theoretical risk of antepartum fetal bleeding or maternal intrapartum or postpartum bleed. ${ }^{1}$ But to date, no studies were able to prove the efficacy of such practice in reducing bleeding.

Plasmapheresis has been reported as an effective solution in providing instantaneous symptomatic relief in cases of pruritus refractory to medical therapy. ${ }^{75}$

\section{Assessment of Fetal Well-Being}

The reduction in perinatal mortality rates observed in recent years could be partly attributed to closer surveillance during pregnancy and elective delivery by 37 weeks' gestation. ${ }^{2,41}$ However, at present, there is no ideal method of fetal surveillance in patients with ICP. The inability of regular antenatal surveillance like nonstress tests to predict fetal outcome has been noted by several investigators. ${ }^{40,76}$ Despite that, the use of fetal monitoring can be of reassurance to the mother and the physician at the time it is performed and might incidentally capture the acute anoxic event.

There is generally lack of intrauterine growth restriction in cases of intrauterine fetal death in women with ICP, making uteroplacental insufficiency a less likely cause for this complication. ${ }^{16,41}$ The most important implication for this is that there is no need for frequent growth scans in women with ICP.

\section{Gestational Age for Delivery}

Until now, there have been no clear guidelines for the most appropriate gestational age for the delivery of patients with ICP. The target is to reduce symptoms in the mother and decrease the risk of fetal distress, sudden fetal death, and preterm delivery. Management options can be divided into active and expectant.

The use of expectant management carries with it the risk of adverse pregnancy outcome. Alsulyman et al found an increased risk of adverse perinatal outcome in ICP patients and higher incidence of fetal death even after reassuring antenatal testing. ${ }^{40}$ Besides that, regular sonographic assessment cannot influence management because infants usually have appropriate weight for their gestational age. ${ }^{40}$ This might be due to the pathology of ICP, where the cause of death is not a chronic process affecting the placenta but rather an acute event resulting in sudden cardiac arrest. Recently the use of expectant management in a study done in Saudi Arabia including 76 patients with ICP showed no difference in fetal outcome between patients with ICP and normal pregnancy except for an increased risk of nonreassuring fetal heart rate or passage of meconium. ${ }^{77}$

Active management is defined differently by different practitioners but in most cases, closer fetal surveillance, amniocentesis at 36 weeks for detection of meconium and documentation of lung maturity, and induction of labor at 37 weeks are recommended. Induction at 37 weeks is based on the fact that most cases of stillbirths reported in literature occurred close to 38 weeks' gestation. ${ }^{1,78}$ In one study, amniocentesis was able to detect meconium-stained amniotic fluid in less than half of the cases. ${ }^{41}$ The presence of meconium-stained amniotic liquor is a very bad indicator of fetal outcome, with percentages of intrauterine fetal death associated with this condition as high as 86 to $100 \%{ }^{20}$

TBA levels seem to be an important player in deciding on management options. A linear association is found between TBA levels and fetal complications. Lee et al showed a $19.7 \%$ increased risk of meconium passage for each $10 \mu \mathrm{mol} / \mathrm{L}$ increase in TBA concentration. ${ }^{79}$ Glantz et al in their study on bile acid levels and fetal complication rates found no rise in complications until TBA levels exceeded $40 \mu \mathrm{mol} / \mathrm{L}$. Consequently, expectant management might be reasonable and cost-effective when TBA levels are below $40 \mu \mathrm{mol} / \mathrm{L}^{45}$

Whether to manage ICP patients expectantly or actively remains controversial. Some studies support the practice of active management and report reduction in adverse fetal outcomes with no fetal mortality. ${ }^{9,41,78}$ Others support it but at the same time cannot disregard the increased risks associated with induction of labor that early, such as the increased 


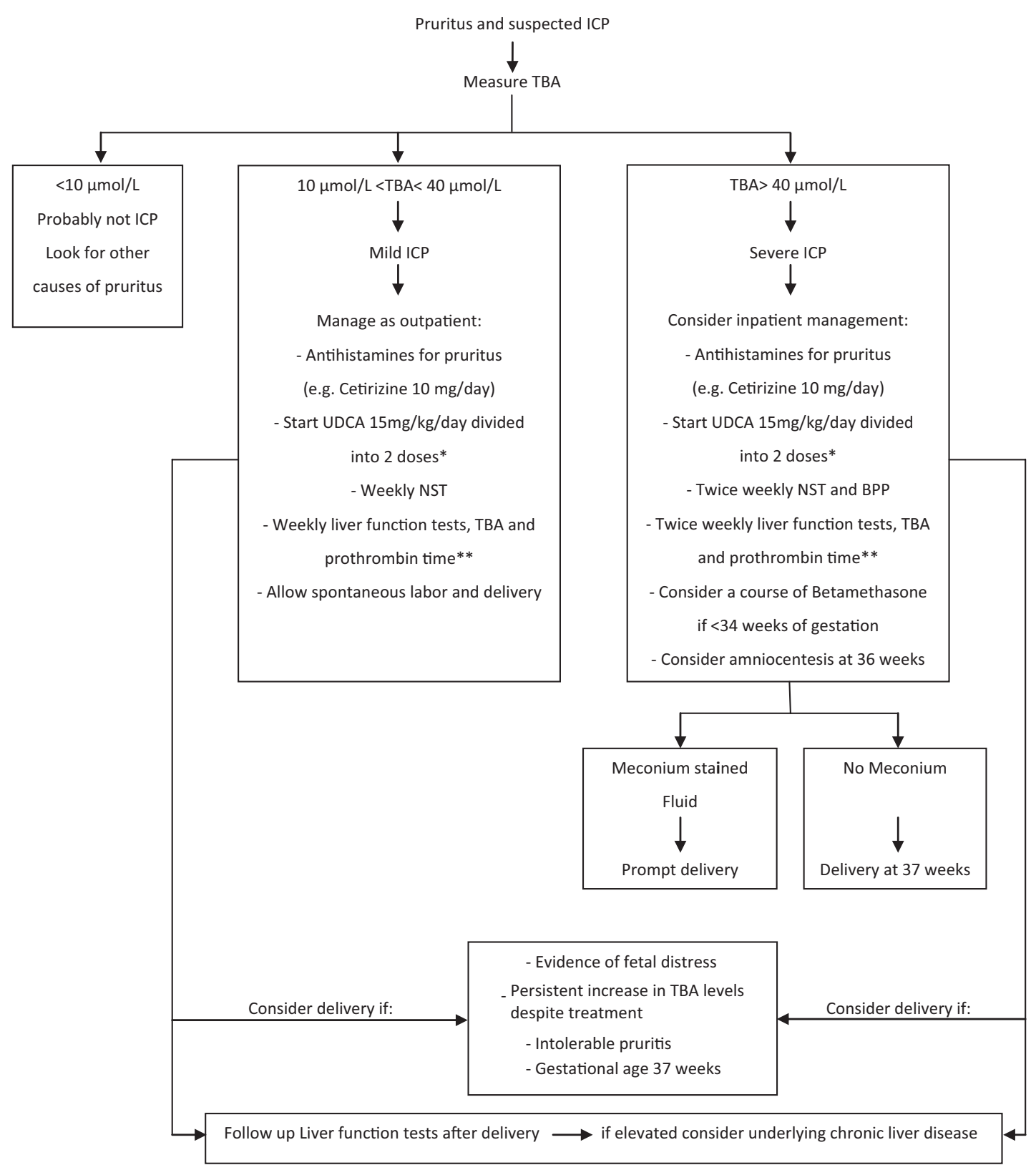

Fig. 1 Suggested management algorithm for ICP. *If TBA levels continue to rise or minor response to UDCA is noted, consider combination with Sadenosyl-L-methionine. ${ }^{* *}$ If prothrombin time is increased: start $10 \mathrm{mg}$ vitamin K daily. Abbreviations: BPP, biophysical profile; ICP, intrahepatic cholestasis of pregnancy; NST, nonstress test; TBA, total bile acid concentration; UDCA, ursodeoxycholic acid.

cesarean delivery rates and the increased risks of admission to the neonatal intensive care unit. ${ }^{33}$ In a recent study where patients with ICP were randomized to early delivery versus expectant management, there was no increased risk of cesarean section in patients assigned to early delivery. ${ }^{57} \mathrm{~A}$ recent statement by the Royal College of Obstetrics and Gynecology suggested that there is insufficient evidence to support or refute the popular practice of early induction and that the management of ICP patients and time of delivery has to be individualized; based on weighing the risk of a preterm delivery and the risk of intrauterine fetal death ${ }^{80}$ After ruling out entities that mimic ICP like viral hepatitis, exposure to hepatotoxic drugs (e.g., acetaminophen overdose), cholelithi- asis, preeclampsia, and acute fatty liver of pregnancy, we suggest the management algorithm shown in - Fig. 1.

\section{Counseling Regarding Future Pregnancies}

Although the disease usually completely resolves postpartum, the recurrence rate has been reported to be up to $90 \%$ in following pregnancies. ${ }^{14}$ It is also to be noted that $20 \%$ of patients with ICP experience cyclic pruritus at time of ovulation or in late luteal phase, and others can have pruritus with the intake of OCP. ${ }^{14}$ Specific attention has to be drawn to patients with prolonged cholestasis after delivery. ICP might be the first manifestation of familial chronic liver disease. ${ }^{23}$ 
On long-term follow-up, patients with ICP showed increased risk of developing biliary and liver disease including gallstones, hepatitis $\mathrm{C}$ and autoimmune hepatitis, nonalcoholic cirrhosis, and pancreatitis. ${ }^{81,82}$

\section{Conclusion}

ICP is a pregnancy-related condition, affecting patients in their second or third trimester mainly and resolving postpartum. The etiology behind it is not fully understood but appears to be multifactorial with genes, diet, and hormones as contributing factors. The dreaded consequences of this condition do not relate to the mother but rather to the fetus. ICP is associated with an increased risk of fetal distress, preterm labor and delivery, meconium staining, and unexplained fetal demise. This requires a twofold management plan that focuses on relieving maternal symptoms that can be achieved by the use of UDCA and at the same time ensuring an optimal pregnancy outcome. This necessitates closer monitoring of the fetus and probably earlier delivery at 37 weeks to decrease fetal morbidity and mortality. This carries with it inherent complications like an increased cesarean section rate and neonatal intensive care unit admissions.

\section{References}

1 Geenes V, Williamson C. Intrahepatic cholestasis of pregnancy. World J Gastroenterol 2009;15:2049-2066

2 Riely CA, Bacq Y. Intrahepatic cholestasis of pregnancy. Clin Liver Dis 2004;8:167-176

3 Lee RH, Goodwin TM, Greenspoon J, Incerpi M. The prevalence of intrahepatic cholestasis of pregnancy in a primarily Latina Los Angeles population. J Perinatol 2006;26:527-532

4 Laifer SA, Stiller RJ, Siddiqui DS, Dunston-Boone G, Whetham JC. Ursodeoxycholic acid for the treatment of intrahepatic cholestasis of pregnancy. J Matern Fetal Med 2001;10:131-135

5 Reyes H. Review: intrahepatic cholestasis. A puzzling disorder of pregnancy. J Gastroenterol Hepatol 1997;12:211-216

6 Reyes H, Gonzalez MC, Ribalta J, et al. Prevalence of intrahepatic cholestasis of pregnancy in Chile. Ann Intern Med 1978;88:487-493

7 Reyes H. Sex hormones and bile acids in intrahepatic cholestasis of pregnancy. Hepatology 2008;47:376-379

8 Lammert F, Marschall HU, Glantz A, Matern S. Intrahepatic cholestasis of pregnancy: molecular pathogenesis, diagnosis and management. J Hepatol 2000;33:1012-1021

9 Rioseco AJ, Ivankovic MB, Manzur A, et al. Intrahepatic cholestasis of pregnancy: a retrospective case-control study of perinatal outcome. Am J Obstet Gynecol 1994;170:890-895

10 Koivurova S, Hartikainen AL, Karinen L, et al. The course of pregnancy and delivery and the use of maternal healthcare services after standard IVF in Northern Finland 1990-1995. Hum Reprod 2002;17:2897-2903

11 Paternoster DM, Fabris F, Palù G, et al. Intra-hepatic cholestasis of pregnancy in hepatitis C virus infection. Acta Obstet Gynecol Scand 2002;81:99-103

12 Goulis DG, Walker IA, de Swiet M, Redman CW, Williamson C. Preeclampsia with abnormal liver function tests is associated with cholestasis in a subgroup of cases. Hypertens Pregnancy 2004;23:19-27

13 Heinonen S, Kirkinen P. Pregnancy outcome with intrahepatic cholestasis. Obstet Gynecol 1999;94:189-193

14 Williamson C, Hems LM, Goulis DG, et al. Clinical outcome in a series of cases of obstetric cholestasis identified via a patient support group. BJOG 2004;111:676-681
15 Johnson P, Samsioe G, Gustafson A. Studies in cholestasis of pregnancy. I. Clinical aspects and liver function tests. Acta Obstet Gynecol Scand 1975;54:77-84

16 Pathak B, Sheibani L, Lee RH. Cholestasis of pregnancy. Obstet Gynecol Clin North Am 2010;37:269-282

17 Brites D, Rodrigues CM, van-Zeller H, Brito A, Silva R. Relevance of serum bile acid profile in the diagnosis of intrahepatic cholestasis of pregnancy in an high incidence area: Portugal. Eur J Obstet Gynecol Reprod Biol 1998;80:31-38

18 Reyes H, Báez ME, González MC, et al. Selenium, zinc and copper plasma levels in intrahepatic cholestasis of pregnancy, in normal pregnancies and in healthy individuals, in Chile. J Hepatol 2000;32:542-549

19 Kauppila A, Korpela H, Mäkilä UM, Yrjänheikki E. Low serum selenium concentration and glutathione peroxidase activity in intrahepatic cholestasis of pregnancy. Br Med J (Clin Res Ed) 1987;294:150-152

20 Mays JK. The active management of intrahepatic cholestasis of pregnancy. Curr Opin Obstet Gynecol 2010;22:100-103

21 Reyes H, Simon FR. Intrahepatic cholestasis of pregnancy: an estrogen-related disease. Semin Liver Dis 1993;13:289-301

22 Meng LJ, Reyes H, Palma J, Hernandez I, Ribalta J, Sjövall J. Profiles of bile acids and progesterone metabolites in the urine and serum of women with intrahepatic cholestasis of pregnancy. J Hepatol 1997;27:346-357

23 Leevy CB, Koneru B, Klein KM. Recurrent familial prolonged intrahepatic cholestasis of pregnancy associated with chronic liver disease. Gastroenterology 1997;113:966-972

24 Müllenbach R, Bennett A, Tetlow N, et al. ATP8B1 mutations in British cases with intrahepatic cholestasis of pregnancy. Gut 2005; 54:829-834

25 Jacquemin E, Cresteil D, Manouvrier S, Boute O, Hadchouel M. Heterozygous non-sense mutation of the MDR3 gene in familial intrahepatic cholestasis of pregnancy. Lancet 1999;353:210-211

26 Smith AJ, de Vree JM, Ottenhoff R, Oude Elferink RP, Schinkel AH, Borst P. Hepatocyte-specific expression of the human MDR3 Pglycoprotein gene restores the biliary phosphatidylcholine excretion absent in Mdr2 (-/- ) mice. Hepatology 1998;28:530-536

27 Dixon PH, Weerasekera N, Linton KJ, et al. Heterozygous MDR3 missense mutation associated with intrahepatic cholestasis of pregnancy: evidence for a defect in protein trafficking. Hum Mol Genet 2000;9:1209-1217

28 Wasmuth HE, Glantz A, Keppeler H, et al. Intrahepatic cholestasis of pregnancy: the severe form is associated with common variants of the hepatobiliary phospholipid transporter $\mathrm{ABCB} 4$ gene. Gut 2007;56:265-270

29 Eloranta ML, Häkli T, Hiltunen M, Helisalmi S, Punnonen K, Heinonen S. Association of single nucleotide polymorphisms of the bile salt export pump gene with intrahepatic cholestasis of pregnancy. Scand J Gastroenterol 2003;38:648-652

30 Huang L, Zhao A, Lew JL, et al. Farnesoid X receptor activates transcription of the phospholipid pump MDR3. J Biol Chem 2003;278:51085-51090

31 Savander M, Ropponen A, Avela K, et al. Genetic evidence of heterogeneity in intrahepatic cholestasis of pregnancy. Gut 2003;52:1025-1029

32 Floreani A, Carderi I, Paternoster D, et al. Hepatobiliary phospholipid transporter $A B C B 4$, MDR3 gene variants in a large cohort of Italian women with intrahepatic cholestasis of pregnancy. Dig Liver Dis 2008;40:366-370

33 Kenyon AP, Piercy CN, Girling J, Williamson C, Tribe RM, Shennan AH. Obstetric cholestasis, outcome with active management: a series of 70 cases. BJOG 2002;109:282-288

34 Berg B, Helm G, Petersohn L, Tryding N. Cholestasis of pregnancy. Clinical and laboratory studies. Acta Obstet Gynecol Scand 1986;65:107-113

35 Kenyon AP, Piercy CN, Girling J, Williamson C, Tribe RM, Shennan AH. Pruritus may precede abnormal liver function tests in 
pregnant women with obstetric cholestasis: a longitudinal analysis. BJOG 2001;108:1190-1192

36 Reyes H, Radrigan ME, Gonzalez MC, et al. Steatorrhea in patients with intrahepatic cholestasis of pregnancy. Gastroenterology 1987;93:584-590

37 Huang WM, Gowda M, Donnelly JG. Bile acid ratio in diagnosis of intrahepatic cholestasis of pregnancy. Am J Perinatol 2009; 26:291-294

38 Dann AT, Kenyon AP, Seed PT, Poston L, Shennan AH, Tribe RM. Glutathione S-transferase and liver function in intrahepatic cholestasis of pregnancy and pruritus gravidarum. Hepatology 2004;40:1406-1414

39 Olsson R, Tysk C, Aldenborg F, Holm B. Prolonged postpartum course of intrahepatic cholestasis of pregnancy. Gastroenterology 1993;105:267-271

40 Alsulyman OM, Ouzounian JG, Ames-Castro M, Goodwin TM. Intrahepatic cholestasis of pregnancy: perinatal outcome associated with expectant management. Am J Obstet Gynecol 1996;175 (4 Pt 1):957-960

41 Fisk NM, Storey GN. Fetal outcome in obstetric cholestasis. Br J Obstet Gynaecol 1988;95:1137-1143

42 Reid R, Ivey KJ, Rencoret RH, Storey B. Fetal complications of obstetric cholestasis. BMJ 1976;1:870-872

43 Shaw D, Frohlich J, Wittmann BA, Willms M. A prospective study of 18 patients with cholestasis of pregnancy. Am J Obstet Gynecol 1982;142(6 Pt 1):621-625

44 Vanjak D, Moreau R, Roche-Sicot J, Soulier A, Sicot C. Intrahepatic cholestasis of pregnancy and acute fatty liver of pregnancy. An unusual but favorable association? Gastroenterology 1991;100: 1123-1125

45 Glantz A, Marschall HU, Mattsson LA. Intrahepatic cholestasis of pregnancy: relationships between bile acid levels and fetal complication rates. Hepatology 2004;40:467-474

46 Rook M, Vargas J, Caughey A, Bacchetti P, Rosenthal P, Bull L. Fetal outcomes in pregnancies complicated by intrahepatic cholestasis of pregnancy in a Northern California cohort. PLoS ONE 2012;7: e28343

47 Brites D. Intrahepatic cholestasis of pregnancy: changes in maternal-fetal bile acid balance and improvement by ursodeoxycholic acid. Ann Hepatol 2002;1:20-28

48 Gorelik J, Shevchuk A, de Swiet M, Lab M, Korchev Y, Williamson C. Comparison of the arrhythmogenic effects of tauro- and glycoconjugates of cholic acid in an in vitro study of rat cardiomyocytes. BJOG 2004;111:867-870

49 Sheikh Abdul Kadir SH, Miragoli M, Abu-Hayyeh S, et al. Bile acidinduced arrhythmia is mediated by muscarinic M2 receptors in neonatal rat cardiomyocytes. PLoS ONE 2010;5:e9689

50 Sepúlveda WH, González C, Cruz MA, Rudolph MI. Vasoconstrictive effect of bile acids on isolated human placental chorionic veins. Eur J Obstet Gynecol Reprod Biol 1991;42:211-215

51 He MM, Liu ZF, Wang XD. [Decreased volume of placental lobular villi vessels in patients with intrahepatic cholestasis of pregnancy]. Sichuan Da Xue Xue Bao Yi Xue Ban 2011;42:797-801

52 Zecca E, De Luca D, Barbato G, Marras M, Tiberi E, Romagnoli C. Predicting respiratory distress syndrome in neonates from mothers with intrahepatic cholestasis of pregnancy. Early Hum Dev 2008;84:337-341

53 Zecca E, De Luca D, Marras M, Caruso A, Bernardini T, Romagnoli C. Intrahepatic cholestasis of pregnancy and neonatal respiratory distress syndrome. Pediatrics 2006;117:1669-1672

54 Mazzella G, Rizzo N, Salzetta A, Iampieri R, Bovicelli L, Roda E. Management of intrahepatic cholestasis in pregnancy. Lancet 1991;338:1594-1595

55 Zapata R, Sandoval L, Palma J, et al. Ursodeoxycholic acid in the treatment of intrahepatic cholestasis of pregnancy. A 12-year experience. Liver Int 2005;25:548-554

56 Mazzella G, Rizzo N, Azzaroli F, et al. Ursodeoxycholic acid administration in patients with cholestasis of pregnancy: effects on primary bile acids in babies and mothers. Hepatology 2001;33:504-8. Erratum in: Hepatology 2002 May;35(5):1291.

57 Chappell LC, Gurung V, Seed PT, Chambers J, Williamson C, Thornton JG; PITCH Study Consortium. Ursodeoxycholic acid versus placebo, and early term delivery versus expectant management, in women with intrahepatic cholestasis of pregnancy: semifactorial randomised clinical trial. BMJ 2012;344:e3799

58 Bacq Y, Sentilhes L, Reyes HB, et al. Efficacy of ursodeoxycholic acid in treating intrahepatic cholestasis of pregnancy: a meta-analysis. Gastroenterology 2012;143:1492-1501 [Epub ahead of print]

59 European Association for the Study of the Liver. EASL Clinical Practice Guidelines: management of cholestatic liver diseases. J Hepatol 2009;51:237-267

60 Paumgartner G, Beuers U. Ursodeoxycholic acid in cholestatic liver disease: mechanisms of action and therapeutic use revisited. Hepatology 2002;36:525-531

61 Serrano MA, Brites D, Larena MG, et al. Beneficial effect of ursodeoxycholic acid on alterations induced by cholestasis of pregnancy in bile acid transport across the human placenta. J Hepatol 1998;28:829-839

62 Macias RI, Pascual MJ, Bravo A, et al. Effect of maternal cholestasis on bile acid transfer across the rat placenta-maternal liver tandem. Hepatology 2000;31:975-983

63 Serrano MA, Macias RI, Vallejo M, et al. Effect of ursodeoxycholic acid on the impairment induced by maternal cholestasis in the rat placenta-maternal liver tandem excretory pathway. J Pharmacol Exp Ther 2003;305:515-524

64 Poupon R, Chrétien Y, Chazouillères O, Poupon RE. Pregnancy in women with ursodeoxycholic acid-treated primary biliary cirrhosis. J Hepatol 2005;42:418-419

65 Korkut E, Kisacik B, Akcan Y, Belenli O, Bicik Z, Yucel O. Two successive pregnancies after ursodeoxycholic acid therapy in a previously infertile woman with antimitochondrial antibodynegative primary biliary cirrhosis. Fertil Steril 2005;83: 761-763

66 Brites D, Rodrigues CM. Elevated levels of bile acids in colostrum of patients with cholestasis of pregnancy are decreased following ursodeoxycholic acid therapy [see comments]. J Hepatol 1998;29: 743-751

67 Azzaroli F, Turco L, Lisotti A, Calvanese C, Mazzella G. The pharmacological management of intrahepatic cholestasis of pregnancy. Curr Clin Pharmacol 2011;6:12-17

68 Hirvioja ML, Tuimala R, Vuori J. The treatment of intrahepatic cholestasis of pregnancy by dexamethasone. Br J Obstet Gynaecol 1992;99:109-111

69 Glantz A, Marschall HU, Lammert F, Mattsson LA. Intrahepatic cholestasis of pregnancy: a randomized controlled trial comparing dexamethasone and ursodeoxycholic acid. Hepatology 2005; 42:1399-1405

70 Abbasi S, Hirsch D, Davis J, et al. Effect of single versus multiple courses of antenatal corticosteroids on maternal and neonatal outcome. Am J Obstet Gynecol 2000;182:1243-1249

71 Stramentinoli G, Di Padova C, Gualano M, Rovagnati P, Galli-Kienle M. Ethynylestradiol-induced impairment of bile secretion in the rat: protective effects of S-adenosyl-L-methionine and its implication in estrogen metabolism. Gastroenterology 1981;80:154-158

72 Ribalta J, Reyes H, Gonzalez MC, et al. S-adenosyl-L-methionine in the treatment of patients with intrahepatic cholestasis of pregnancy: a randomized, double-blind, placebo-controlled study with negative results. Hepatology 1991;13:1084-1089

73 Nicastri PL, Diaferia A, Tartagni M, Loizzi P, Fanelli M. A randomised placebo-controlled trial of ursodeoxycholic acid and S-adenosylmethionine in the treatment of intrahepatic cholestasis of pregnancy. Br J Obstet Gynaecol 1998;105:1205-1207

74 Binder T, Salaj P, Zima T, Vítek L. Randomized prospective comparative study of ursodeoxycholic acid and S-adenosylL-methionine in the treatment of intrahepatic cholestasis of pregnancy. J Perinat Med 2006;34:383-391 
8 A Review of Intrahepatic Cholestasis of Pregnancy Diken et al.

75 Warren JE, Blaylock RC, Silver RM. Plasmapheresis for the treatment of intrahepatic cholestasis of pregnancy refractory to medical treatment. Am J Obstet Gynecol 2005;192:2088-2089

76 Londero F, San Marco L. Intrahepatic cholestasis of pregnancy: are we really able to predict fetal outcome? Am J Obstet Gynecol 1997; 177:1274

77 Al Shobaili HA, Hamed HO, Al Robaee A, Alzolibani AA, Amin AF, Ahmad SR. Obstetrical and fetal outcomes of a new management strategy in patients with intra-hepatic cholestasis of pregnancy. Arch Gynecol Obstet 2011;283:1219-1225

78 Roncaglia N, Arreghini A, Locatelli A, Bellini P, Andreotti C, Ghidini A. Obstetric cholestasis: outcome with active management. Eur J Obstet Gynecol Reprod Biol 2002;100:167-170
79 Lee RH, Kwok KM, Ingles S, et al. Pregnancy outcomes during an era of aggressive management for intrahepatic cholestasis of pregnancy. Am J Perinatol 2008;25:341-345

80 Obstetric Cholestasis. RCOG Green-top Guideline No. 43, May 2011. Available at: http://www.rcog.org.uk/files/rcog-corp/ GTG43obstetriccholestasis.pdf. Accessed October 15, 2012

81 Furhoff AK. Itching in pregnancy. A 15-year follow-up study. Acta Med Scand 1974;196:403-410

82 Ropponen A, Sund R, Riikonen S, Ylikorkala O, Aittomäki K. Intrahepatic cholestasis of pregnancy as an indicator of liver and biliary diseases: a population-based study. Hepatology 2006;43: 723-728 